\title{
Reviews of high arsenic tailings stabilization technology and application
}

\author{
Liu Yuhui ${ }^{1, a}$, Yu Qingfeng ${ }^{1}$ \\ ${ }^{1}$ School of Environmental Science and Engineering, Guilin University of Technology ,Guilin, \\ 541006, China \\ am13633628083@163.com
}

Keywords: arsenic; tailings; stabilization technology

Abstract. This paper reviews the properties and hazards of arsenic, the source and hazards of high arsenic tailings, as well as the latest research progress to world abroad on phytoremediation and physical and chemistry repair of high arsenic tailings, and the future prospects of the tailings processing.

\section{The properties and Azards of Arsenic}

The Properties Of Arsenic And Arsenic Compounds. Arsenic (As) is located in Group VA of the Periodic Table as well as in metal and nonmetal transition region with atomic number 33 and atomic weight 74.92. And it is ubiquitous toxic metalloid elements in the soil and mainly exists in the form of sulfide on the earth's crust about $2-5 \mathrm{mg} / \mathrm{kg}$, and often associated in metallic minerals. There are also independent minerals $\left(\mathrm{As}_{2} \mathrm{~S}_{3} / \mathrm{As}_{3} \mathrm{~S}_{4}\right)$.It is easy to be absorbed by human cells and leading to arsenic poisoning because the chemical properties similar to phosphorus [1].

The main arsenic compounds are arsenic trioxide $\left(\mathrm{As}_{2} \mathrm{O}_{3}\right)$ and arsine $\left(\mathrm{AsH}_{3}\right)$. Arsenic trioxide $\left(\mathrm{As}_{2} \mathrm{O}_{3}\right)$ also known as arsenite anhydride, a white powdery solid; Arsine is a colorless gas with a slight odor of garlic. In addition to arsenic trisulfide $\left(\mathrm{As}_{2} \mathrm{~S}_{3}\right)$, arsenic pentoxide $\left(\mathrm{As}_{2} \mathrm{O}_{5}\right)$, arsenic trichloride $\left(\mathrm{AsCl}_{3}\right)$ and arsenic trioxide $\left(\mathrm{H}_{3} \mathrm{AsO}_{3}\right)$ [2]. There is rarely elemental arsenic in nature.

Hazard Of As And Its Compounds. Arsenic and arsenic compounds with different forms of existence contain different toxicity.Toxicity of arsenic compounds decreased in the following order: hydrogen arsenide (Inorganic or organic matter) $>$ arsenious oxide $>$ Arsenite(inorganic) $>$ arsenic acid $>$ arsenic compound > elemental arsenic [3]. The toxicity of elemental arsenic is low. It is almost impossible to be absorbed and easily excreted from the body when it enters the body through digestive tract. Arsenic poisoning effect on the human body is divided into acute and chronic. Phenomena of chronic arsenic poisoning: in addition to the plant neurasthenia, there are skin hyperpigmentation "black disease", hyperkeratosis, peripheral neuritis, vasospasm and limb necrosis "Blackfoot disease". Arsenic in air can cause skin and respiratory tract irritation, skin rashes, dermatitis, ulcers and nasal septum perforation embolism. More acute arsenic poisoning events caused by consumption of arsenic-contaminated food, water or swallowed arsenic pesticides [4].

\section{The Source and Harm of Arsenic Tailings}

Source Of Arsenic Tailings. The mining industry as the second human activities has a long history. At the same time it also resulting a series of environmental problems in the world, such as emissions of acidic waste water, the accumulation of solid waste and dust pollution. Waste rock, tailings, slag, fly ash and dust generated in Mining and metallurgy activities are the leading solid waste in the world. The largest discharge of industrial solid waste industry in China is metal mine industry, tailings emissions reached 50 billion tons and increase at a rate of 2-3 million tons per year [5]. If improperly disposed, these mines solid waste will lead to geological disasters, engineering disasters, environmental pollution, vegetation destruction, land degradation, desertification and a series of environmental problems.

High arsenic tailings are large amounts of solid powder produced, after the mining process: ore crushing, ore flotation and ore refining [6]. In the arsenic mineral development process, part of the 
arsenic was transferred metal concentrate, and other part was turn into the tailings. Fig. 1 shows the direction of arsenic in the process of selecting and smelting [7].

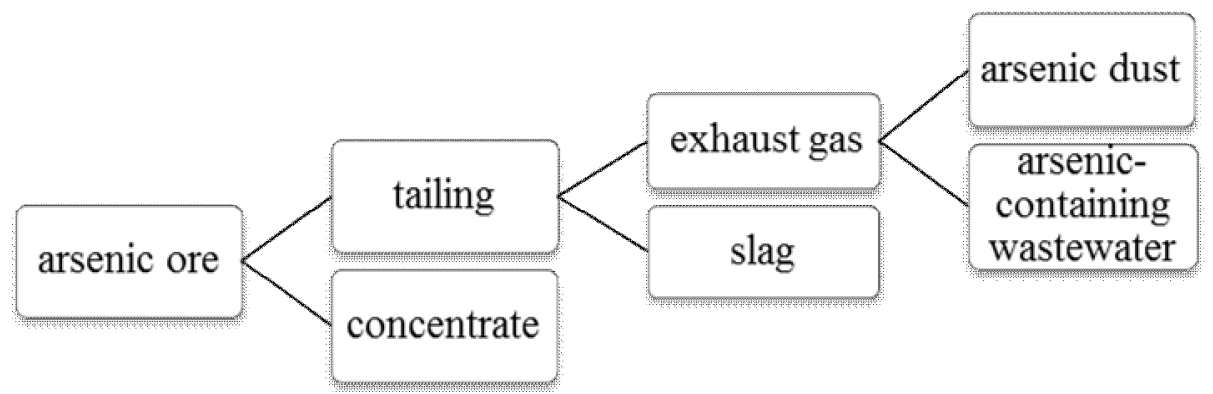

Fig. 1 Arsenic in the process of selecting and smelting plant

Hazard Of Arsenic Tailings. Harm to the environment caused by tailings contain: (1) On the conditions of tailings stacked in the surface, small particles of tailings oxidation were changed after oxidation, hydrolysis and weathering reaction, which lead to arsenic component orginally will not be transferred into component can be migranted; (2)By interacting with Tailings, surface water of Tailings dumps sites dissolve some harmful components (including arsenic) and transfer them, which causing massive pollution [8]; (3) The metal mines tailings particle were carried by wind after drying because they are very fine, so it is easy to cause dust and pollution, and then spread farther through the air and lead to poisoning through respiration;(4) It is easy to occur flow, collapse and landslides in tailing pond, especially in large dams over 100 meters of tailings. If an accident occurs, these mine tailings will directly excrete in lakes and rivers, then polluting water, clogging the river and leading to major disaster. Arsenic tailings has become one of an important sources of arsenic contamination in metal mines. For example, in the metal sulfide ore tailings, As mainly exists in the form of arsenic sulfide minerals (such as arsenopyrite) or oxide minerals (such as scorodite) $[9,10]$. In the oxidation, arsenic tailings occurs activation and release, then migrated by surface water, which made soil and water around the tailings were polluted [11].

The mine tailings arsenic pollution incidents have occurred sometimes. Arsenic contamination incidents occurred in Yangzonghai,Yunnan, 2008, which directly threaten 2 million people's safety of drinking water around lake and affected crop irrigation which caused threat for hundreds of residents on both sides of livelihood, at the same time, tourism also suffered great losses [12]. Because of arsenic contamination of water, nearly 200 people were poisoned, in Wuxu, HeChi, 2004 [13]. It happened again and led to 450 local people were poisoned [14]. The main reason is in the upper reaches of the giant mine tailings oxidize in a long time and release acid water of arsenic which finally enter human body through the food chain and lead poisoning.

\section{High Arsenic Tailings stabilization Techniques}

Stabilization Technology Summary. For a long time, the treatment and disposal of metal mine tailings and waste are generally used the way of accumulating waste. Not only occupy a lot of land and pollute soil, surface water and groundwater, but also many extended or overload tailings exists a great risk. In addition to the construction, management of tailings also needs to cost a lot of money. At present, heavy metal contaminated tailings remediation technology in domestic and foreign can be divided into two categories: One aim is to reduce pollution and risks. the state of existence of heavy metals in the tailings is changed since heavy metals are stabilized or fixed, so that their activity, toxicity, migration, transformation and bioavailability in the environment. In addition, there are a variety of techniques to eliminate heavy metals in the tailings are reduced the content of heavy metals. According to different mode of action, physical, chemical and biological repair methods have formed. Choosing which method depends on the properties and the type of tailings, the type and extent of pollution, end-use and repair costs. 
Physicochemical Remediation. Solidification / stabilization technology (S/S technology for short)-adding solidification / stabilization agent to the tailings for reducing the leaching toxicity, mobility and bioavailability of heavy metals which dissolved in the environment by the effect of adsorption of heavy metal, ion exchange, precipitation or co-precipitation, complexation or chelation to change its existent form in the tailings,so the infiltration or leaching of rainwater harm to plants and animals is reduced [15]. United States, Japan and some European countries has been conducted a lot of research about tailings wastelands of Solidification / Stabilization Remediation Technology and have developed the appropriating technical guidelines and specifications [16]. According to site remediation techniques annual reports, from 1982 to 2005 years, has $22.2 \%$ of contaminated sites in the US Superfund program using a solidification/stabilization technology repair [17]. Solidification/ Stabilization technology in domestic were more used cement and fly ash for Curing or Stabilizing heavy metal sludge form leather, paper and other processing, and there are more Solidification / Stabilization technology are applied in engineering practice, but more research of dealing with heavy metal tailings is at the laboratory or small-scale field trials and lack of a wide range of engineering applications. It is confirm that a number of industrial byproducts and some minerals, such as lime, fly ash, mud and zeolite, $\mathrm{Pb}$, $\mathrm{Cd}, \mathrm{Cu}, \mathrm{Zn}, \mathrm{Cr}$, As and other heavy metals can be effectively stabilized, which leading to greatly reduced leaching toxicity. The method of curing can solidify heavy metals in situ and greatly reduced costs.

At present, the commonly used stabilizers are alkaline materials (lime, fly ash, and silicon, calcium carbonate), phosphate (phosphate rock, hydroxyapatite, calcium hydrogen phosphate), clay minerals (zeolite, bentonite and meerschaum) and organic fertilizers (farmyard manure, green manure, peat, municipal sewage sludge and others). Different curing agents have different fixed mechanisms of heavy metal [18], such as lime can reduce heavy metal mobility mainly by response of hydrolysis reaction by themselves and co-precipitation with calcium carbonate. Cement curing is a method of regarding cement as cured agent to deal with hazardous wastes. When cured, cement and water or separately added water form waste water have hydration reaction to produce gel, which wastes harmful particles were wrapped up and gradually hardened into cement cured. Cement solidification is one of the main methods for handling hazardous wastes, and the cement solidification technique were known as the best disposal of hazardous wastes by the EPA. The molten thermoplastic material (asphalt, waxes, polyethylene, polypropylene, etc.) were mixed with hazardous waste at high temperatures in order to achieve the objective of curing on its stability. Currently, the most commonly used thermoplastic curing technology in the world abroad is asphalt curing technology. Glass solidification, which is a method that untreated wastes mixed with fine glass to form glass liquid at high temperature with dense crystalline structure of vitreous, ensure permanent stability in solidifying.

Solidification/stabilization technology was applied to arsenic-contaminated soil at earliest. Tailings generally contains a mixture of soil, different sizes of gravel, tailings, other wastes and their weathering products, so it is quite different form the normal soil[19]. Choi et al. [20] have investigated that the effects of the added amount of cement to heavy metals arsenic and lead leaching rate. As a result, the leaching concentration of arsenic and lead lower than limit value when the amount of cement content was $7.5 \%$. Palfy et al. [21] mixed the arsenic-containing sludge with cement and ferrous salt. It was shows hat the leaching concentration of arsenic reduced from $6430 \mathrm{mg} / \mathrm{L}$ to $0.823 \mathrm{mg} / \mathrm{L}$ after curing treatment. Q.Wang and C.J Ferron has been cured arsenic residue with asphalt, the results indicate that cured body capacity ratio is small and leachability is low, meanwhile has a strong effect against microbial attack.

Phytoremediation. It has been found that Brake, Pteris vittata, Pteris cretica and other plants have superior effect with enriched arsenic in soil [22]. In recent years, Pteris vittata and Pityrogramma calomelanos are found that grow in high-arsenic soil. They are perennial plants and have large of biomass, which distributed in subtropical and temperate regions of the south. According to currently experiment results, Pteris vittata's capacity of absorb arsenic in soil several times higher than other plants, even 10-20 times [23,24]. Chen Tongbin et al. [25] based on field surveys and cultivation 
experimental in Hunan Province, found that the distribution of arsenic in arsenic Hyperaccumulator centipede grass is significantly different from ordinary plants: pinna> petiole> root. Indoor cultivation research have found that the amount of arsenic in pinna can up to $5070 \mathrm{mg} / \mathrm{kg}$ and Pteris vittata grow fast, and have large of biomass, wide geographical distribution and fine adaptability. Therefore, we can grow a lot of plants on both sides of the river to absorb arsenic and safely handle after harvest, finally, the contaminant can be removed. For example, tailings around the Weihe River carried out Stereoscopic Agriculture ecological management, not only reclaimed land, reasonably utilized tailings resources and reinforced embankments, but also realized gardening and protected the ecological environment. It create a direct and effective new way to make full use of tailings resources, land, energy, materials, environmental protection, and waste utilization and push comprehensive utilization of tailings into a new field.

In future, we can use biotechnology and genetic engineering of plants and screen out plants which can fix arsenic contamination [26]. Using biochemical techniques to identify the genetic code that can make high metal accumulation factor transfer into a larger biomass and non-edible plants. The application of modern molecular biology and genetic engineering techniques can make the biological traits of Hyperaccumulator (individual size, biomass, growth rate, growth cycle, etc.) can be further improved and increased. Gene engineering bacteria which can effectively degrade contaminant are built. The application of gene engineering bacteria can be improved the efficiency.

\section{Conclusions}

With the depletion of mineral resources and mineral processing technology improving, especially in recent years, a sharply rise in commodity prices, the issues on secondary utilization of ore resources are popping out day after day. This will not only make effective utilization of the tailings and obtain economic benefits, but also largely reduce arsenic and sulfur pollution of tailings in natural environment.

\section{References}

[1] E.J. Tokar, L. Benbrahim-Tallaa, J.M. Ward, et al: Crit. Rev. Toxicol Vol. 40 (2010), p. 912-927

[2] M. Lim, G.C. Han, J.W. Ahn, et al: Int. J. Environ. Res. Pub. Heal Vol. 6 (2010), p. 2865

[3] Xinkang Cao: In-situ status and releasing characteristics of the arsenic presence in the tailings of the Gannan tungsten mining area and its surrounding soils(In Chinese)(Jiangxi University of Science and Technology, Ganzhou 2013).

[4] Qiuya Niu:Research of the cleaner technologies about the treatment of arseine pollution and the recovery of arsenic resources(In Chinese) (Hunan University, Hunan 2001).

[5] Yao Liu:Research on the green development indices of the metallic mines in China(In Chinese) (China University of Geosciences, Beijing 2012).

[6] Yuan Tian, Guangyi Fu, Dongsheng Zou, et al: Ecol. Eng Vol. 32 (2014), p. 685-688(In Chinese)

[7] Changluo Zhu, Mingwei Shen and Hualun Li: Multipurpose. Util. Miner. Resour Vol. 5 (2005), p. 31-34(In Chinese)

[8] C. Kohfahl, T. Graupner, C. Fetzer, et al: Sci. Total. Environ Vol. 408 (2010), p. 5932-5939

[9] Ke Zeng:Study on the flotation behavior and separation of sulfur-arsenic mineral(In Chinese) (Zhongnan University, Changsha 2010).

[10]Pan Wu, Congqiang Liu and Yuangen Yang: Mineralogica. Sinica Vol.21 (2001), p. 213-218(In Chinese)

[11]P. Nunez, H.K. Hansen, S. Aguirre, et al: Sep. Purif. Technol Vol.79 (2011), p. 285-290

[12] Yuxi Zhang, Xiaoping Xiang, Ying Zhang, et al: Environ. Sci Vol.33 (2012), p. 3768-3777(In Chinese)

[13] Yikai Li and Baojiang Yang: Land. Resources. S. China Vol.5 (2004), p. 20-21,24(In Chinese) 
[14]Haihong Li, Zhidan Mai, Caiqian Huang, et al: China. Occupational. Med Vol.38(2011), p. 177-178(In Chinese)

[15] Hongcai Wang:Soil remediation technology research of washing and solidification/stabilization for heavy metal contaminated soil(In Chinese) (Zhejiang University, Hangzhou 2014).

[16]B.D. Bone-B, L.H. Bamard-L and C.D. Hills-C, in: Guidance on the use of stabilization / solidification for the treatment of contaminated soil. edited by UK Environment Agency(2004).

[17]Hanzhou Hao, Tongbin Chen, Menggui Jin, et al: J. Appl. Ecol Vol.22(2011), p. 816-824(In Chinese)

[18] Xuegang Wang, Guanghui Wang and Jinsheng Liu: Ind. Safety. Environ. Protec Vol.36(2010), p. 29-31(In Chinese)

[19]M. Kent: Appl. Geog Vol.2(1982), p. 83-107

[20] W.H. Choi, S.R. Lee and J.Y. Park: Waste. Manage Vol.29(2009), p. 1766-1771

[21]P. Palfy, E. Vircikova and L. Molnar: Waste. Manage Vol.19(1999), p. 55-59

[22] G.P. Warren, B.J. Alloway, N.W. Lepp, et al: Sci. Total. Environ Vol.(2003), p. 255-257

[23]Hongling Shen, Zhenyan He and Mi Ma: Plant. Physiology Vol.50(2014), p. 591-598(In Chinese)

[24]E.O. Kartinen, C.J. Martin: Desalination Vol.103(1995). p. 79-88

[25] Tongbin Chen, Chaoyang Wei, Zechun Huang, et al: China. Academic. Journal Vol.47(2002). p. 207-210(In Chinese)

[26] Yuanli Zhi, Weima Zong, et al: Sci. Total. Environ Vol.(2014). p. 468-469(In Chinese) 